Fetal Diagnosis and Therapy

\title{
Isolated Ascites in a Monochorionic Twin after Fetoscopic Laser Ablation Is Not Necessarily Secondary to Recurrence or Anaemia: Bowel Complications in Twin-to-Twin Transfusion Syndrome after Fetoscopic Laser Ablation
}

\author{
Lee Na Tan ${ }^{a, b}$ Ka Wang Cheung ${ }^{a, c}$ Isaac Philip ${ }^{d}$ Stephen Ong ${ }^{e}$ \\ Mark David Kilby, $f$ \\ ${ }^{a}$ Fetal Medicine Centre, Birmingham Women's and Children's NHS Foundation Trust, Birmingham, UK; ${ }^{b}$ Department \\ of Obstetrics and Gynaecology, Hospital Raja Permaisuri Bainun, Ipoh, Malaysia; ' Department of Obstetrics and \\ Gynaecology, Queen Mary Hospital, The University of Hong Kong, Hong Kong, Hong Kong SAR; d Department of \\ Paediatric Surgery, Royal Belfast Hospital for Sick Children, Northern Ireland, Belfast, UK; ${ }^{\circ}$ Department of Obstetrics

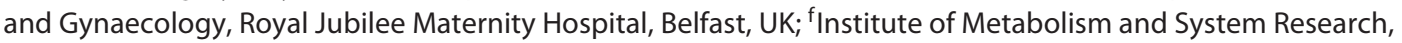 \\ College of Medical and Dental Sciences, University of Birmingham, Edgbaston, UK
}

\section{Keywords}

Twin-to-twin transfusion syndrome · Fetoscopic laser ablation · Jejunal atresia - Ileal atresia · Necrotising enterocolitis - Bowel perforation

\footnotetext{
Abstract

Background/Purpose: We report a case study of jejunal atresia and the results of a systematic literature review of all reported cases of bowel complications occurring after fetoscopic laser ablation (FLA) for the treatment of twin-to-twin transfusion syndrome (TTTS). Methods: A systematic literature review was performed of bowel complications after FLA for TITS according to PRISMA guidelines. Results: There are 11 published cases of small bowel atresia, 5 cases of necrotising enterocolitis (NEC), and 2 cases with foetal bowel perfo-
}

rations. Recipient twins were more likely to be affected by small bowel atresia (7 recipient and 4 donor cases) and NEC (3 recipient and 2 donor twins). Prenatal ultrasonographic abnormalities were demonstrated in 7 out of 9 cases with bowel atresia and in both cases of bowel perforation. The overall survival rate for neonates with bowel complications after FLA is $72 \%$, but is much lower for co-twins at $22 \%$. The survival rates for jejunoileal atresia and NEC are 91 and 40\%, respectively. Conclusions: It is uncertain as to whether these bowel anomalies are due to bowel ischaemia associated with TTTS, the treatment with FLA, or a combination of both. Cases with prenatal abdominal ultrasonographic abnormalities after FLA should have close prenatal and postnatal assessment to detect bowel complications.

(C) 2018 S. Karger AG, Base

\section{KARGER}

(c) 2018 S. Karger AG, Basel

E-Mail karger@karger.com

www.karger.com/fdt
Lee $\mathrm{Na}$ Tan

Fetal Medicine Department

Birmingham Women's Hospital

Birmingham B15 2TG (UK)

E-Mail tanleena2011@gmail.com 


\section{Introduction}

Twin-to-twin transfusion syndrome (TTTS) complicates up to $15 \%$ of all monochorionic (MC) pregnancies and carries a high mortality rate $(80-100 \%)$ if untreated [1]. Fetoscopic laser ablation (FLA) improves the survival of at least one foetus in up to 85-90\%, and FLA using the "Solomon technique" produces the best outcomes in reducing complications of twin anaemia polycythaemia sequence [2]. There are various post-fetoscopic laser complications in foetuses associated with ischaemia, including neurological handicap (secondary to strokes), bowel atresia, necrotising enterocolitis (NEC), and skin necrosis [3]. It is uncertain whether these are associated with the TTTS itself, its treatment, or a combination of the two. Bowel complications in MC twins complicated by TTTS with or without treatment by FLA are uncommon, and the underlying aetiology is poorly understood.

We report a single case study of jejunal atresia in a foetus whose twin pregnancy was complicated by TTTS and treated by FLA, and we also present the results of a systematic literature review of all reported cases of bowel complications associated with this condition.

\section{Case Report}

A 26-year-old nulliparous woman with a MC diamniotic twin pregnancy was diagnosed with Quintero stage III (recipient) TTTS and selective intrauterine growth restriction of the donor twin (sIUGR) at 16 weeks and 5 days of gestation, and was referred to our tertiary centre for treatment. The "donor" twin had severe oligohydramnios (deepest vertical pool $=1 \mathrm{~cm}$ ) with absent end diastolic velocimetry on umbilical artery (UA) Doppler velocimetry. The recipient twin had polyhydramnios (deepest vertical pool = $9 \mathrm{~cm}$ ) with ultrasound evidence of a distended foetal bladder, tricuspid regurgitation, and abnormal intra-foetal Doppler flow (raised pulsatility index on UA Doppler and absent velocity during atrial contraction in the ductus venosus [DV] Doppler waveform). The percentage difference in estimated foetal weight was $32 \%$, and no structural anomalies were visualised on ultrasound scan for both foetuses.

FLA was performed on the day after diagnosis under sedation and local anaesthesia. A trocar and $2 \mathrm{~mm}$ fetoscope was inserted under ultrasound visualisation into the recipient sac. The placenta was located anteriorly on the uterine wall, and direct visualisation of the inter-twin membrane was achieved. Chorionic plate vasculature was mapped from the cord insertions between the donor and recipient cords. Aberrant vascular anastomoses were then ablated by employing a selective sequential technique and the "Solomon technique" using diode laser at a power of 30-60 W. A total of 9 anastomoses (all arterio-venous) were identified and coagulated, followed by amniodrainage with $1,500 \mathrm{~mL}$ of amniotic fluid removed to achieve a maximum pool depth of $6 \mathrm{~cm}$. The duration of the procedure was $30 \mathrm{~min}$. Transabdominal sonography $2 \mathrm{~h}$ af- ter FLA revealed viable foetuses, and there were no septostomies or chorioamniotic separations.

Sadly, the donor foetus died within one week from FLA. Serial ultrasound sonography was performed for the surviving recipient twin at weekly intervals. The first follow-up scan one week after FLA revealed normal UA and middle cerebral artery (MCA) Doppler scans but an elevated peak velocity index for veins (PVIV) of the DV Doppler, which normalised during a repeat scan the week after. In utero scan of the foetal brain using magnetic resonance imaging (MRI) was performed at 24 weeks demonstrating no foetal brain anomaly in the surviving twin (ex-recipient). The surviving foetus showed no anomaly on ultrasound examination until 22 weeks and 6 days of gestation ( 6 weeks after FLA), when isolated ascites (free fluid in the abdominal cavity) was detected, and the measured peak systolic velocimetry of the MCA was $<1.5 \mathrm{MoM}$ (indicating a low probability of foetal anaemia). The UA Doppler was normal, but the PVIV of the DV Doppler was again elevated. Serial ultrasound scanning noted the disappearance of the ascites within 5 days with normalisation of DV Doppler, and ultrasonography follow-ups were unremarkable subsequently until delivery.

At 27 weeks of gestation, the pregnancy was complicated by preterm premature rupture of membrane but managed conservatively. A repeat MRI scan again demonstrated no foetal brain pathology at 29 weeks. At 32 weeks, there were associated uterine contractions that were persistent, and therefore, an emergency Caesarean delivery was performed (birth weight of $1,975 \mathrm{~g}$ ). The baby girl was diagnosed with respiratory distress syndrome and was intubated in the Neonatal Intensive Care Unit. Neonatal haemoglobin on day 1 was $148 \mathrm{~g} / \mathrm{dL}$, and platelet count was normal at $330 \times 10^{9} / \mathrm{L}$.

An abdominal X-ray performed to confirm the position of the endotracheal tube raised suspicions of bowel obstruction, and jejunal atresia was diagnosed subsequently. Laparotomy was performed on day 3 of life, which revealed malrotation of the gut with evidence of a sealed jejunal perforation just proximal to the area of jejunal atresia. The atretic segment was resected with an end-toend anastomosis, and a Ladd's procedure for malrotation was done. The baby made an unremarkable recovery following the surgery and was discharged home on normal feeds at the equivalent of 38 weeks of gestation.

\section{Methods of Systematic Review of the Literature}

A systematic literature review of bowel complications after FLA for TTTS was performed according to the PRISMA guidelines. The PubMed database was searched electronically with a combination of keywords for "twin-to-twin transfusion syndrome," "jejunal atresia," "bowel ischaemia," "necrotising enterocolitis," "laser," and "fetoscopic." A manual check of the reference list was performed, and there was no restriction of language used. The predefined criterion for study inclusion was bowel complications in twin pregnancies complicated with TTTS after FLA. The titles and abstracts were screened to identify articles fulfilling the criteria. Full text review of these articles was performed, and the reference lists of relevant articles were searched manually to identify additional reports. Because of the rarity of this diagnosis, we accepted single case studies or cohorts of $<5$ cases. Two reviewers (L.N.T. and K.W.C.) performed the searches for articles fulfilling the inclusion and exclusion criteria independently, and any differences were resolved by a third reviewer (M.D.K.).

We extracted the following data from each report: author, publication year, other associated anomalies, karyotyping results, 
Fig. 1. Flow chart for systematic literature search of bowel complications after fetoscopic laser ablation for twin-to-twin transfusion syndrome (up to July 2018).

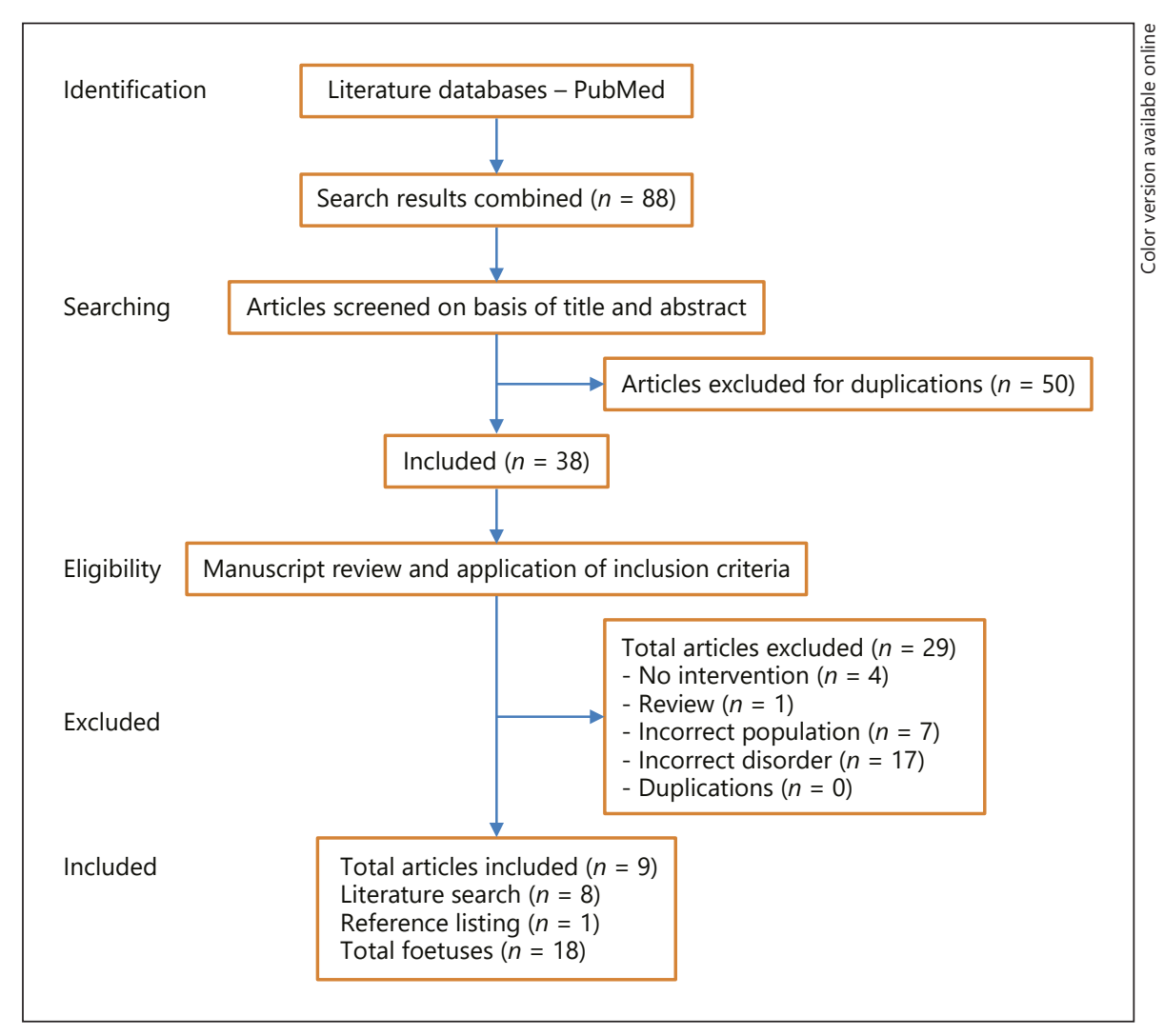

stage of TTTS at diagnosis, gestational age at FLA, antenatal imaging abnormalities, weight differences at birth, haemoglobin at birth for both donor and recipient, site of affected bowel, outcome of donor and recipient twins, gestational age at delivery, mode of delivery, and postpartum management.

\section{Results}

The search resulted in the review of 88 articles, 9 papers $(10.2 \%)$ of those 88 met the final inclusion criteria. Figure 1 is an algorithm of the selection process and inclusion of studies in this review. A total of 18 cases (together with our present case) are included in our study. Cases number 6 and 7 as well as 11 and 12 are donor and recipient twins from the same pregnancies, where both twins suffered from bowel complications; therefore, these 18 cases are reported from $16 \mathrm{MC}$ pregnancies (Table 1 ).

The Quintero stage of TTTS at diagnosis and FLA was mostly severe ( $\geq$ Quintero stage II) in 13 cases; whereas in 1 case, FLA was done for TTTS stage 1 , and the stage of disease was not mentioned for the remaining 2 cases (Table 1). The median gestational age at development of
TTTS was 18 weeks (ranging between 16 and 20 weeks), while the median gestational age at the time of FLA was also 18 weeks (ranging between 16 and 25 weeks). There is no mention of additional structural anomalies in 6 pregnancies, and 3 neonates out of the remaining 10 pregnancies (30\%) have additional anomalies: pulmonary stenosis in 2 cases and congenital cystic adenomatoid malformation of the lung in 1 case (Table 1).

There are 11 reported cases of small bowel atresia ( 8 ileal, 3 jejunal), 5 cases of NEC, and 2 cases with foetal bowel perforations after FLA for TTTS (Table 2). Recipient twins are affected by small bowel atresia in 7 and donor twins in 4 cases. Similarly, there is a predominance of recipient twins being affected by NEC, with 3 recipients versus 2 donor twins (Table 2). For cases 11 and 12, both twins are from the same pregnancy and had ascites and echogenic bowel from prenatal scans. The donor twin had transverse colon perforation leading to meconium peritonitis without requiring bowel resection. Similarly, the recipient twin had meconium peritonitis, but this was secondary to small bowel perforation at the jejunum and required resection and double stoma. No atretic segments were found in the intestinal tract of the recipient, but 
Table 1. Publication details and characteristics of the cases

\begin{tabular}{|c|c|c|c|c|c|c|c|c|}
\hline $\begin{array}{l}\text { Case } \\
\text { No. }\end{array}$ & First author & $\begin{array}{l}\text { Publication } \\
\text { year }\end{array}$ & $\begin{array}{l}\text { Type of } \\
\text { study }\end{array}$ & $\begin{array}{l}\text { Stage of } \\
\text { TTTS }\end{array}$ & \multicolumn{2}{|l|}{ GA at } & $\begin{array}{l}\text { Karyo- } \\
\text { typing }\end{array}$ & Other associated anomalies (case; co-twin) \\
\hline 2 & Arul [4] & 2001 & Case series & $\mathrm{N} / \mathrm{A}$ & $19 \mathrm{w}$ & N/A & N/A & N/A; N/A \\
\hline 3 & Schnater [5] & 2005 & Case report & Severe & $20 \mathrm{w}$ & $21 \mathrm{w}$ & N/A & N/A; N/A \\
\hline 4 & Huisman [6] & 2005 & Case report & III & N/A & $20 \mathrm{w}$ & N/A & Severe pulmonary stenosis; N/A \\
\hline 5 & Morikawa [7] & 2008 & Case series & II & $18 \mathrm{w}$ & $19 \mathrm{w}$ & $46 \mathrm{XX}$ & No; No \\
\hline 9 & Saura [9] & 2010 & Case series & II & $16 \mathrm{w}$ & $16 \mathrm{w}$ & N/A & No; No \\
\hline 10 & Saura [9] & 2010 & Case series & II & $17 \mathrm{w}$ & $17 \mathrm{w}$ & $\mathrm{N} / \mathrm{A}$ & CCAM; No \\
\hline $11,12^{\dagger \dagger}$ & Marcellin [10] & 2012 & Case report & II & $17 \mathrm{w}$ & $18 \mathrm{w}$ & $46 \mathrm{XY}$ & $\mathrm{N} / \mathrm{A} ; \mathrm{N} / \mathrm{A}$ \\
\hline 13 & Sanchez-Galan [11] & 2017 & Case series & III & N/A & $18 \mathrm{w}$ & N/A & N/A; Pulmonary stenosis \\
\hline 14 & Sanchez-Galan [11] & 2017 & Case series & I & N/A & $19 \mathrm{w}$ & N/A & No; No \\
\hline 15 & Sanchez-Galan [11] & 2017 & Case series & III & $\mathrm{N} / \mathrm{A}$ & $20 \mathrm{w}$ & N/A & N/A; Hypertension and septal hypertrophy \\
\hline 16 & Sanchez-Galan [11] & 2017 & Case series & II & N/A & $21 \mathrm{w}$ & N/A & N/A; No \\
\hline
\end{tabular}

TTTS, twin-to-twin transfusion syndrome; GA, gestational age; FLA, fetoscopic laser ablation; N/A, not available; w, weeks; d, days; CCAM, congenital cystic adenomatoid malformation. ${ }^{\dagger}$ Case 6 is donor and Case 7 is recipient in the same pregnancy. ${ }^{\dagger \dagger}$ Case 11 is donor and Case 12 is recipient in the same pregnancy.

there were necrotic patches scattered throughout the jejunum with microemboli seen.

In more than half of the cases ( 8 out of 14 cases; no findings reported for 2 other pregnancies), imaging abnormalities of the abdomen were seen on prenatal scans. The features seen were dilated loops of bowel ( 6 cases, resolved prior to delivery in 1 case), ascites ( 5 cases, resolved prior to delivery in 1 case), calcification (1 case), and echogenic bowel ( 3 cases). Prenatal abdominal sonographic anomalies were more commonly seen in cases with bowel atresia (7 out of 9 reported cases) but not reported for NEC (out of 3 reported cases). For cases 11 and 12 with isolated bowel perforation, ascites and echogenic bowel suggestive for meconium peritonitis were detected antenatally.

All neonates with NEC were born prematurely, with one at 34 weeks (moderate to late preterm), one at 31 weeks (very premature), and three cases born before 28 weeks (extremely premature). In the postnatal life, the timing of clinical manifestation for NEC is mostly late, with 1 case diagnosed within the first 2 days of life, and the remaining 4 cases presented later with surgery performed more than a week after birth (between day 9 to day 18 after delivery). For neonates with small bowel atresia, most surgeries ( 9 out of 11 cases) were performed within the first 3 days of life, except for 2 cases who were operated on day 14 and day 23 after birth. Almost all cases with bowel complications had surgery done (17 out of 18) except for the case reported by Huisman et al. [6], where the baby had severe pulmonary stenosis requiring dilatation at day 1 and subsequently died at day 4 with severe NEC.

The overall survival rate in neonates with bowel complications after FLA is $72 \%$, whereas it is much lower for the co-twin at $22 \%$ (however, there are no details of preor post-FLA sonographic findings to suggest reasons for the lower survival rate of the co-twins). The survival rates decrease with gestational age at birth (Table 3). The outcomes are more favourable for neonates with jejunoileal atresia compared to NEC, with survival rates of 91 and $40 \%$, respectively (Table 3 ). Complete data about survival outcomes (both for case and co-twin) for each pregnancy are available for 11 out of 16 pregnancies: with survival of both twins in 2 pregnancies $(18 \%$; 1 bowel atresia and 1 NEC), 1 twin in 8 pregnancies ( $73 \%$; 5 bowel atresia, 2 NEC, and 1 bowel perforation), and neither twin in 1 pregnancy (9\%; NEC) (Table 2). In the remaining 5 pregnancies (all cases had bowel atresia), 4 neonates affected by bowel complications survived but no information was available for their co-twins.

Weight differences at birth was reported in 8 pregnancies in whom both twins survived to birth, and 3 of these pregnancies had weight discrepancies of $>20 \%$ (Table 2 ): these are cases 6 and 7, where both twins from the same pregnancy had NEC and died; case 9 (donor, smaller twin), who had jejunal atresia and both case and co-twin survived; and case 15 (donor, smaller twin), who was diagnosed with ileal atresia and survived but no informa- 


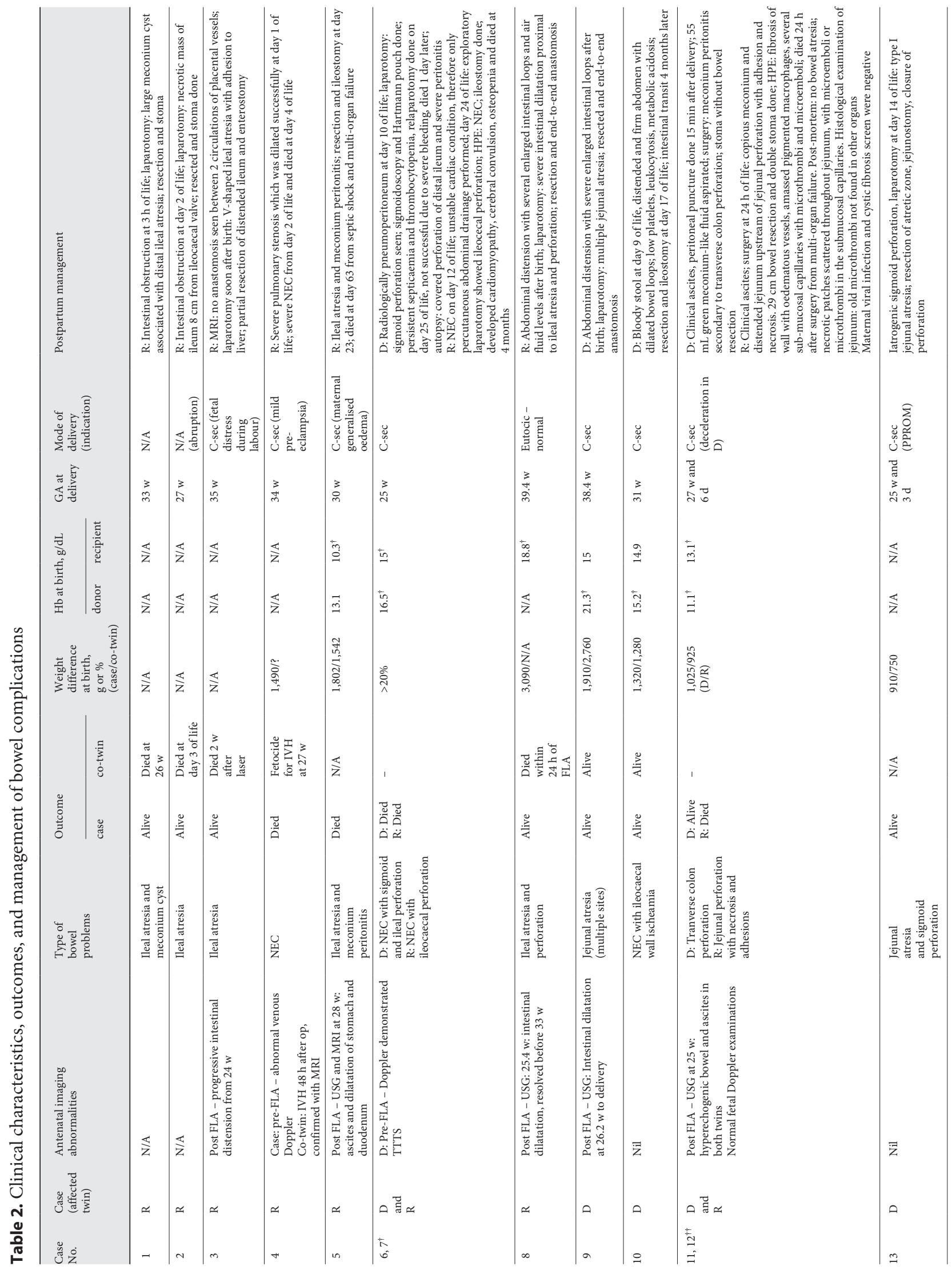




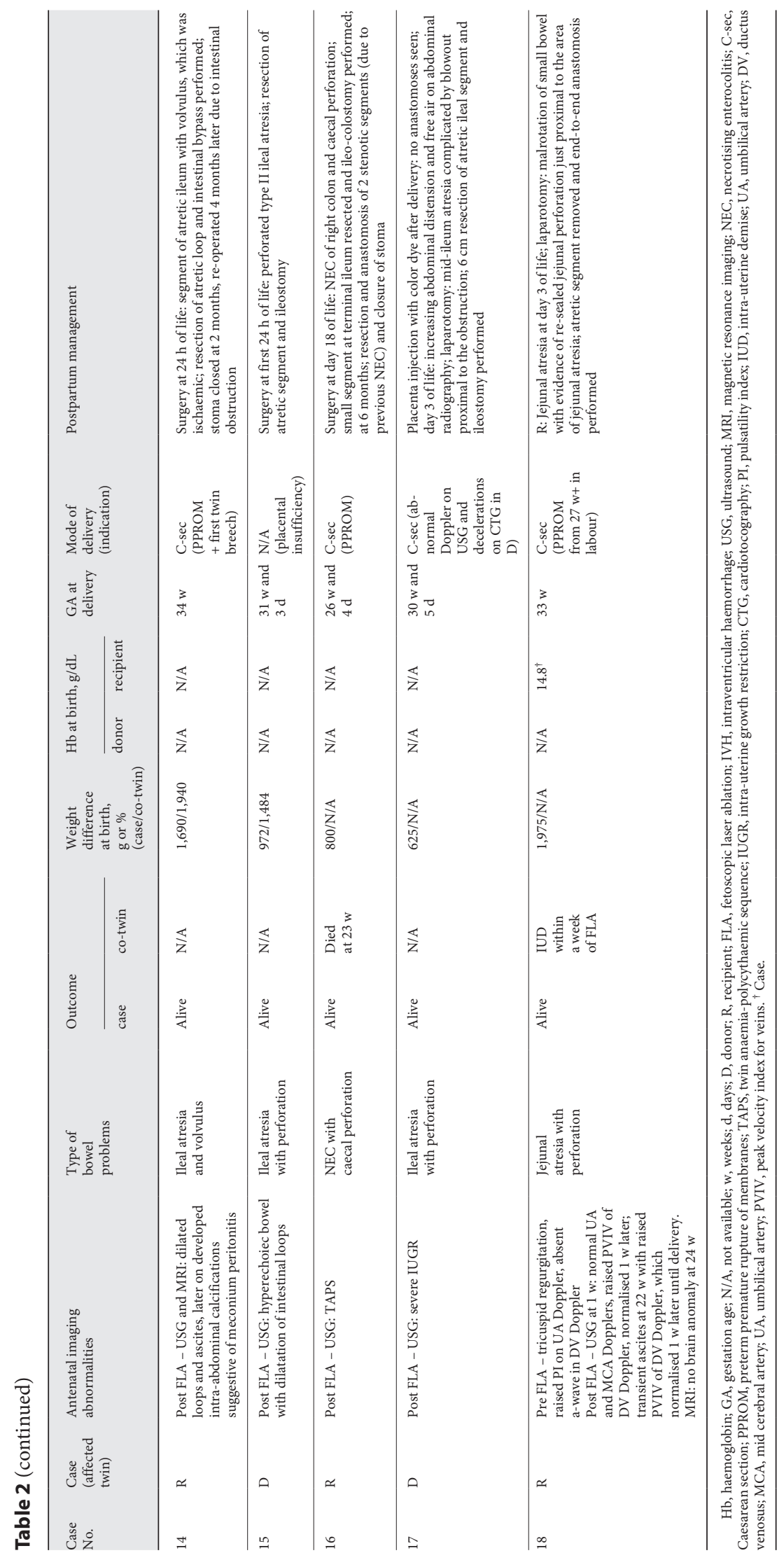


Table 3. Survival rates for fetuses affected by bowel complications

\begin{tabular}{|c|c|c|c|}
\hline & $\begin{array}{l}\text { Survivors, } \\
n\end{array}$ & $\begin{array}{l}\text { Cases where data } \\
\text { is available }\end{array}$ & $\begin{array}{l}\text { Survival } \\
\text { rate, } \%\end{array}$ \\
\hline Case (overall) & 13 & 18 & 72 \\
\hline Term $(>37$ weeks $)$ & 2 & 2 & 100 \\
\hline Moderate to late preterm (32-37 weeks) & 4 & 5 & 80 \\
\hline Very preterm (28-32 weeks) & 3 & 4 & 75 \\
\hline Co-twin (overall) & 2 & 9 & 22 \\
\hline \multicolumn{4}{|c|}{ Survivors in each pregnancy (no data available for co-twins in 5 pregnancies) } \\
\hline Both twins & 2 & 11 & 18 \\
\hline One twin & 8 & 11 & 73 \\
\hline No survivor & 1 & 11 & 9 \\
\hline \multicolumn{4}{|c|}{ Survival according to type of bowel complications (Cases) } \\
\hline
\end{tabular}

Total number of pregnancies: 16. Total number of cases: 18 (cases 6 and 7 as well as cases 11 and 12 are donor and recipient twins from the same pregnancies).

tion was available for co-twin. For the remaining 5 pregnancies with birth weight differences of $<20 \%, 2$ neonates died (case 5 with ileal atresia in the heavier recipient twin and case 12 with bowel perforation in the smaller recipient twin). Among the 4 neonates who survived, 3 were donor twins (cases 10,11, and 13), who were born heavier than their co-twins, and 1 was a recipient twin (case 14), who weighed less at birth than the co-twin.

Haemoglobin results were extracted from 5 pregnancies, and the differences in haemoglobin levels between donor and recipient twins are $0.3 \mathrm{~g} / \mathrm{dL}$ (both case and cotwin survived), $1.5 \mathrm{~g} / \mathrm{dL}$ (both had NEC and died), $2.0 \mathrm{~g} /$ dL (affected donor with higher haemoglobin level survived, affected recipient died), $2.8 \mathrm{~g} / \mathrm{dL}$ (affected recipient with lower haemoglobin died, outcome of co-twin unknown), and $6.3 \mathrm{~g} / \mathrm{dL}$ (both donor with higher haemoglobin and co-twin survived) (Table 2).

Most of these cases were delivered by Caesarean section (12 out of 13 reported pregnancies) (Table 2).

\section{Discussion}

Our case study is important as it reminds foetal medicine and neonatal specialists that isolated ascites noted on ultrasound after treatment for TTTS is not necessarily secondary to either recurrence or foetal anaemia but may be secondary to in utero bowel perforation.

Bowel Complications in TTTS after FLA
The total prevalence of jejunoileal atresia in singleton pregnancies with normal karyotype is 0.7 per 10,000 live births from the EUROCAT registers between 1990 and 2006 [13]. In this study, 21 cases out of 423 with jejunoileal atresia were twins, although the chorionicities of these pregnancies were not known [13]. In 1994, the study by Cragan et al. [14] has suggested an association between small intestinal atresia and monozygotic twinning, where monozygotic twins are at increased risk of having small bowel atresia compared to singletons.

Based on our results, small bowel atresia occurs more commonly in the ileum compared to the jejunum in MC twins complicated by TTTS and treated by FLA, which is similar to the prevalence of small intestinal atresia in all births, with a predominance for ileal atresia [15]. Mesenteric ischaemia in MC twins is postulated to be due to hypoperfusion and/or hyperviscosity associated with vascular anastomoses in TTTS, haemodynamic alteration where there is demise of a co-twin, or a thromboembolic phenomenon after laser ablation of the vascular anastomoses $[4,5,9]$. There is no report of duodenal atresia after FLA in the literature, probably because the aetiology for duodenal atresia is attributed to developmental failure of recanalisation rather than ischaemia [16].

Chiang et al. [17] reported that donor twins are at increased risk of hypoperfusion to the gastrointestinal tract and hypoxaemic damage leading to bowel complications. Differences in haemoglobin levels between donor and re- 
cipient twins have been suggested to be the cause of bowel complications, especially in donor twins and those with anaemia [17]. On the contrary, our results have shown that recipient twins are at a higher risk of having bowel complications following FLA compared to donor twins, both from small bowel atresia and NEC. Donor twins also have higher haemoglobin levels than recipient twins in 4 out of 5 cases, which makes anaemia a less likely explanation for bowel complications (although haemoglobin levels are not reported for most cases, presumably because most co-twins died before delivery and, therefore, no blood samples would be available for analysis).

Marcellin et al. [10] reported that the recipient twin showed evidence of microthrombi and microemboli both in post-operative and post-mortem specimens. However, the mechanism of this extensive bowel thromboembolic event confined to the jejunum is unknown. Due to the small number of cases available currently, more in-depth studies are required to ascertain the exact underlying pathologies of bowel complications after FLA.

Prenatal sonographic findings (dilated foetal bowel loops, enlarged stomach, echogenic bowel, polyhydramnios) are seen in $34-87 \%$ of all cases with postnatal diagnosis of jejunoileal atresia $[18,19]$. Most of the cases in our systematic review (64\%) with jejunoileal atresia after FLA had prenatal sonographic evidence of bowel abnormalities, which was described as transient in some foetuses. Consideration could be given to perform in utero MRI in cases with abnormal post-operative prenatal sonography to aid in diagnosing bowel atresia and possibly the underlying cause such as thromboembolism. In 2005, Huisman et al. [6] has demonstrated the utility of in utero MRI to evaluate post-operative changes in the placenta in addition to the more routine assessment of foetal central nervous system, as MRI is not limited by maternal bowel gas or overlying bony structures compared to ultrasonography. This is further supported by reports regarding the superiority of foetal MRI in overcoming the limitations associated with sonography, such as operator dependence, inherent inferior image contrast, patient factors such as obesity and small field of view, and non-specific US findings which may relate to transient normal variants [20$22]$. The detection of jejunal and ileal atresia with US alone is low with detection rates of 66.3 and $25.9 \%$, respectively, and MRI has been shown to improve detection of small and large bowel obstructions, malrotation, and perforations resulting in meconium peritonitis or pseudocyst [20-23]. Although jejunoileal atresia is associated with a good survival rate, surgical therapy should be expedited; hence, cases with prenatal suspicions warrant careful postnatal assessment with plain abdominal radiograph or enema studies, even if the prenatal ultrasonographic differences have resolved prior to delivery [24].

A prospective multicentre cohort study showed that the incidence of NEC requiring surgical management and spontaneous intestinal perforation (SIP) is approximately $11 \%$ in the most premature babies at extremely low gestational age ( $<25$ weeks), and this risk is similar in singleton and multiple pregnancies [25]. The risk of developing NEC which can be managed medically (without the need for surgical intervention), however, is higher for singleton compared to multiple pregnancies [25]. For the general population, over $90 \%$ of all neonates with NEC are born prematurely, and NEC is associated with a high mortality rate of $70-80 \%$ [26-29]. Survivors may have significant long-term morbidity including short gut syndrome and neurodevelopmental delay [26]. Despite efforts to establish clear diagnostic criteria for NEC, the condition is thought to encompass more than one disease entity, such as isolated intestinal perforation and ischaemic bowel disease due to cardiac anomalies [26]. These emphasise the complexity of diagnosing and managing NEC [26]. The aetiology of NEC is multifactorial and is largely related to the immaturity of the gastrointestinal tract [26]. For neonates with NEC after FLA for TTTS, all were delivered prematurely and, therefore, the most likely aetiology is prematurity rather than a direct consequence of FLA. In our study, none of the neonates with NEC had prenatal sonography abnormalities, and most of them had late presentation of the complication, which makes antenatal detection unlikely and close postnatal monitoring for signs of NEC necessary, especially in neonates born prematurely.

Bowel perforation can be caused by atresia, stenosis, volvulus, internal hernia, intussusception, Meckel's diverticulum, meconium ileus, a peritoneal band, or may be idiopathic [30]. Multiple pregnancy is also associated with a higher risk of developing SIP although the cause is unknown $[25,27]$. SIP is considered a separate clinical entity from NEC and affects neonates earlier in life, particularly neonates with a very low birth weight [31-33]. Therefore, we analysed cases 11 and 12 separately from cases with atresia and NEC because meconium peritonitis in these cases resulted from bowel perforation without evidence of obstruction, and the authors did not classify them as NEC [10]. Tsukimori et al. [31] reported a similar case of SIP in their recipient twin, but the intervention for TTTS was amnioreduction instead of FLA. The authors hypothesised that the perforation in their case was due to an ischaemic event which occurred in utero, based on the surgical and histopathological findings [31]. Tiwari et al. 
[32] reported that unlike NEC, SIP has no long-term gastrointestinal sequelae and is associated with good outcome (100\% survival rate in their series), and thus it is important to distinguish this condition from NEC for prognostic reasons [33].

Based on our results, it is interesting to note that for neonates with birth weight discrepancies of $<20 \%$ compared to their co-twins, most donor twins weighed more than their recipient co-twins at birth after treatment with FLA. Although there is no data available regarding weight discrepancies prior to FLA for the cases in our report, Chmait et al. [34] have demonstrated that donor twins have lower estimated foetal weight compared to recipient twins at the time of diagnosis of TTTS prior to treatment with FLA. Our findings are in concordance with the results from another study by Chmait et al. [35] whereby donor twins exhibit catch-up growth in utero after FLA for TTTS, which continues until 2 years of age. However, MC pregnancies complicated with sIUGR, which is present in our case, have additional risks of intrauterine demise of the growth-restricted twin, especially in the presence of abnormal UA Doppler (20-40\% increased risk) [36]. The normally grown twin is also at risk of concomitant intrauterine death, sequelae of prematurity, and neurological damage [36]. Having stage III TTTS posed additional risk of perinatal death (70-100\% for advanced TTTS) to our recipient twin, if no antenatal treatment was instituted [37].

The main limitation of this review is the small number of cases reported in the literature for intestinal complications after FLA, thereby limiting the interpretation of the values in inter-twin discordances. All publications are case reports or case series, which means there is a publication bias due to the absence of control groups. It is also difficult to conclude whether these bowel complications are due to complications of prematurity, multiple pregnancy, monochorionicity, TTTS, or true iatrogenic consequences from FLA. Given the scarcity of reported cases of bowel complications after FLA in the literature, there is no data about its prevalence, and attempts to collect this information would ideally require a worldwide collaboration from all centres performing FLA for TTTS. In addition, to our knowledge, there is currently no epidemiological study looking at bowel complications in other subgroups of MC pregnancies, such as uncomplicated TTTS, twin anaemia polycythaemia sequence, sIUGR, or early/ untreated TTTS; hence comparison of bowel complications after FLA against these foetuses is not possible. It is pertinent to comprehensively record and report cases with bowel complications after FLA, including prenatal and postnatal investigation findings to ascertain the un- derlying pathology and ascertain if these complications are direct complications from FLA. The use of advanced imaging modalities including serial Doppler studies, in utero foetal or postnatal MRI as well as judicious histopathological examination of placenta and resected bowel specimens may provide further clues about the aetiology of these conditions. Maternal factors such as race, anaemia, smoking status, obesity, and consumption of aspirin have also been found to be associated with increased risks of NEC and SIP and may, therefore, also affect the outcomes of these pregnancies [25].

\section{Conclusion}

Although bowel complications following FLA for TTTS are increasingly detected and reported, it is still a rare complication, and the underlying aetiology remains unknown. Cases with prenatal gastrointestinal sonographic abnormalities should be followed up with postnatal imaging to exclude bowel abnormalities, and neonates, especially those born prematurely, should be monitored closely for signs of bowel perforations.

\section{Acknowledgement}

Mark David Kilby has a project grant from the Richard and Jack Wiseman Trust funded until 2019, investigating screening and outcomes in monochorionic twins.

\section{Statement of Ethics}

The authors have no ethical conflicts to disclose.

\section{Disclosure Statement}

The authors have no conflicts of interest to declare.

\section{Funding Sources}

This research did not receive any specific grants from funding agencies in the public, commercial, or not-for-profit sectors.

\section{Author Contributions}

Study conception and design, data acquisition, analysis and data interpretation, drafting of the manuscript, critical revision: all authors. 


\section{References}

1 Berghella V, Kaufmann M. Natural history of twin-twin transfusion syndrome. J Reprod Med. 2001 May;46(5):480-4.

2 Roberts D, Neilson JP, Kilby MD, Gates S. Interventions for the treatment of twin-twin transfusion syndrome. Cochrane Database Syst Rev. 2014 Jan;30(1):CD002073.

3 Slaghekke F, Lopriore E, Lewi L, Middeldorp JM, van Zwet EW, Weingertner AS, et al. Fetoscopic laser coagulation of the vascular equator versus selective coagulation for twinto-twin transfusion syndrome: an open-label randomised controlled trial. Lancet. 2014 Jun; 383(9935):2144-51.

4 Arul GS, Carroll S, Kyle PM, Soothill PW, Spicer RD. Intestinal complications associated with twin-twin transfusion syndrome after antenatal laser treatment: report of two cases. I Pediatr Surg. 2001 Feb;36(2):301-2.

5 Schnater JM, van Zalen-Sprock RM, Schaap $\mathrm{AH}$, Festen S, Aronson DC. Ileal atresia and thrombo-embolic liver calcifications diagnosed after treatment with intrauterine laser coagulation therapy for twin-to-twin transfusion syndrome: report of 2 cases. J Pediatr Surg. 2005 May;40(5):875-6.

6 Huisman TA, Lewi L, Zimmermann R, Willi UV, Deprest J. Magnetic resonance imaging of the feto-placentar unit after fetoscopic laser coagulation for twin-to-twin transfusion syndrome. Acta Radiol. 2005 May;46(3):328-30.

7 Morikawa M, Sago H, Yamada T, Hayashi S, Yamada T, Cho K, et al. Ileal atresia after fetoscopic laser photocoagulation for twin-totwin transfusion syndrome-a case report. Prenat Diagn. 2008 Nov;28(11):1072-4.

8 Detlefsen B. Boemers TM, Schimke C. Necrotizing enterocolitis in premature twins with twin-to-twin transfusion syndrome. Eur J Pediatr Surg. 2008;18:50-2.

9 Saura L, Muñoz ME, Castañón M, Eixarch E, Corradini M, Aguilar C, et al. Intestinal complications after antenatal fetoscopic laser ablation in twin-to-twin transfusion syndrome. J Pediatr Surg. 2010 Jan;45(1):E5-8.

10 Marcellin L, Quintana A, Essaoui M, Anselem $\mathrm{O}$, Beaudoin S, El Ayoubi M, et al. Meconium peritonitis in both fetuses with early twin-totwin transfusion syndrome. Twin Res Hum Genet. 2012 Aug;15(4):527-31.

11 Sánchez-Galán A, Encinas JL, Antolín E, Vilanova A, Dore M, Triana P, et al. [Intestinal complications in twin-to-twin transfusion syndrome (TTTS) treated by laser coagulation (LC)]. Cir Pediatr. 2017 Jan;30(1):33-8.

12 Piek MW, Oepkes D, Lopriore E, Hulsker CC Ileal blowout due to ileal atresia in a donor with twin-to-twin transfusion after fetoscopic laser surgery. Ann Pediatr Surg. 2018;14(1): $42-3$.
13 Best KE, Tennant PW, Addor MC, Bianchi F, Boyd P, Calzolari E, et al. Epidemiology of small intestinal atresia in Europe: a registerbased study. Arch Dis Child Fetal Neonatal Ed. 2012 Sep;97(5):F353-8.

14 Cragan JD, Martin ML, Waters GD, Khoury MJ. Increased risk of small intestinal atresia among twins in the United States. Arch Pediatr Adolesc Med. 1994 Jul;148(7):733-9.

15 Hemming V, Rankin J. Small intestinal atresia in a defined population: occurrence, prenatal diagnosis and survival. Prenat Diagn. 2007 Dec;27(13):1205-11.

16 Cragan JD, Martin ML, Moore CA, Khoury MJ. Descriptive epidemiology of small intestinal atresia, Atlanta, Georgia. Teratology. 1993 Nov;48(5):441-50.

17 Chiang MC, Lien R, Chao AS, Chou YH, En Chen YJ. Clinical consequences of twin-totwin transfusion. Eur J Pediatr. 2003 Feb; 162(2):68-71.

18 Wax JR, Hamilton T, Cartin A, Dudley J, Pinette MG, Blackstone J. Congenital jejunal and ileal atresia: natural prenatal sonographic history and association with neonatal outcome. J Ultrasound Med. 2006 Mar;25(3): $337-42$.

19 Haeusler MC, Berghold A, Stoll C, Barisic I, Clementi M; EUROSCAN Study Group. Prenatal ultrasonographic detection of gastrointestinal obstruction: results from 18 European congenital anomaly registries. Prenat Diagn. 2002 Jul;22(7):616-23.

20 Rubesova E. Fetal bowel anomalies-US and MR assessment. Pediatr Radiol. 2012 Jan; 42(42 Suppl 1):S101-6.

21 Furey EA, Bailey AA, Twickler DM. Fetal MR Imaging of Gastrointestinal Abnormalities. Radiographics. 2016 May-Jun;36(3):904-17.

22 Rubio EI, Blask AR, Badillo AT, Bulas DI. Prenatal magnetic resonance and ultrasonographic findings in small-bowel obstruction: imaging clues and postnatal outcomes. Pediatr Radiol. 2017 Apr;47(4):411-21.

23 Virgone C, D'antonio F, Khalil A, Jonh R, Manzoli L, Giuliani S. Accuracy of prenatal ultrasound in detecting jejunal and ileal atresia: systematic review and meta-analysis. Ultrasound Obstet Gynecol. 2015 May;45(5): 523-9.

24 Morris G, Kennedy A Jr, Cochran W. Small Bowel Congenital Anomalies: a Review and Update. Curr Gastroenterol Rep. 2016 Apr; 18(4):16.
25 Singh R, Shah B, Allred EN, Grzybowski M, Martin CR, Leviton A; ELGAN Study co-investigators. The antecedents and correlates of necrotizing enterocolitis and spontaneous intestinal perforation among infants born before the 28th week of gestation. J Neonatal Perinatal Med. 2016 May;9(2):159-70.

26 Neu J. Necrotizing enterocolitis: the mystery goes on. Neonatology. 2014;106(4):289-95.

27 Rayyan M, Myatchin I, Naulaers G, Ali Said Y, Allegaert K, Miserez M. Risk factors for spontaneous localized intestinal perforation in the preterm infant. J Matern Fetal Neonatal Med. 2018 Oct;31(19):2617-23.

28 Sharma R, Hudak ML. A clinical perspective of necrotizing enterocolitis: past, present, and future. Clin Perinatol. 2013 Mar;40(1):27-51.

29 Lin PW, Stoll BJ. Necrotising enterocolitis. Lancet. 2006 Oct;368(9543):1271-83.

30 Minato M, Okada T, Miyagi H, Honda S, Takazawa K, Kubota KC, et al. Meconium pseudocyst with particular pathologic findings: a case report and review of the literature. J Pediatr Surg. 2012 Apr;47(4):e9-12.

31 Tsukimori K, Yumoto Y, Masumoto K, Taguchi T, Kondo H, Sueishi K, et al. Ischemic ileal perforation in the donor of monochorionic twins complicated by twin-twin transfusion syndrome. Fetal Diagn Ther. 2009;26(3): 173-6.

32 Tiwari C, Sandlas G, Jayaswal S, Shah H. Spontaneous intestinal perforation in neonates. J Neonatal Surg. 2015 Apr;4(2):14.

33 Meyer CL, Payne NR, Roback SA. Spontaneous, isolated intestinal perforations in neonates with birth weight less than $1,000 \mathrm{~g}$ not associated with necrotizing enterocolitis. J Pediatr Surg. 1991 Jun;26(6):714-7.

34 Chmait RH, Kontopoulos EV, Korst LM, Llanes A, Petisco I, Quintero RA. Stage-based outcomes of 682 consecutive cases of twintwin transfusion syndrome treated with laser surgery: the USFetus experience. Am J Obstet Gynecol. 2011 May;204(5):393.e1-6.

35 Chmait RH, Chon AH, Schrager SM, Kontopoulos EV, Quintero RA, Vanderbilt DL. Donor catch-up growth after laser surgery for twin-twin transfusion syndrome. Early Hum Dev. 2015 Dec;91(12):751-4.

36 Valsky DV, Eixarch E, Martinez JM, Crispi F, Gratacós E. Selective intrauterine growth restriction in monochorionic twins: pathophysiology, diagnostic approach and management dilemmas. Semin Fetal Neonatal Med. 2010 Dec;15(6):342-8.

37 Society of Maternal-Fetal Medicine Publications Committee. Simpson LL. Twin-twin transfusion syndrome. Am J Obstet Gynecol. 2013 May;208(5):392. 